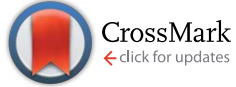

Cite this: RSC Adv., 2017, 7, 5880

Received 24th November 2016 Accepted 29th December 2016

DOI: $10.1039 / \mathrm{c} 6 \mathrm{ra} 27263 \mathrm{k}$

www.rsc.org/advances

\section{The effects of $\mathrm{NaF}$ concentration on electrochemical and corrosion behavior of AZ31B magnesium alloy in a composite electrolyte}

\author{
Jing $\mathrm{Xu}^{\text {a }}$ Qiaoling Yang, ${ }^{\mathrm{a}}$ Muhammad Sufyan Javed, ${ }^{\text {bc }}$ Youlai Gong, ${ }^{\mathrm{a}}$ \\ Muhammad Kashif Aslam ${ }^{a}$ and Changguo Chen*a
}

\begin{abstract}
Electrochemical and corrosion behavior of AZ31B magnesium alloy have been investigated using electrochemical methods in a composite solution of $\mathrm{MgSO}_{4}-\mathrm{Mg}\left(\mathrm{NO}_{3}\right)_{2}\left(0.14 \mathrm{~mol} \mathrm{~L}{ }^{-1} \mathrm{MgSO}, 1.86 \mathrm{~mol}\right.$ $\left.\mathrm{L}^{-1} \mathrm{Mg}\left(\mathrm{NO}_{3}\right)_{2}\right)$ under different sodium fluoride $(\mathrm{NaF})$ concentrations. The surface of the $\mathrm{AZ31B}$ magnesium alloy is characterized using scanning electron microscopy, Fourier transform infrared spectroscopy and X-ray photoelectron spectroscopy. The experimental results indicate that the magnesium electrode achieves a low corrosion rate and high reactivity in the selected composite solution. Furthermore, the effect of $\mathrm{NaF}$ on the AZ31B magnesium alloy in the composite electrolyte is investigated in detail and the results demonstrated that the inhibition efficiency increased up to $80 \%$ and the delay time was reduced by four times when the NaF concentration reaches $30 \mathrm{mmol} \mathrm{L}^{-1}$. Thus, NaF could efficiently reduce corrosion rate and improve the discharge activity of the magnesium anode as it changes the composition of the surface film. We believe that the composite electrolyte of $\mathrm{MgSO}_{4}-$ $\mathrm{Mg}\left(\mathrm{NO}_{3}\right)_{2}$ with optimized concentration of $\mathrm{NaF}$ is a promising candidate for improving the corrosion resistance and reducing the delayed action of AZ31B alloy in aqueous solution.
\end{abstract}

\section{Introduction}

Magnesium ( $\mathrm{Mg}$ ) presents very interesting properties as low electrode potential $(-2.37 \mathrm{~V}$ vs. standard hydrogen electrode) and high faradic capacity of $2202 \mathrm{~mA} \mathrm{~h} \mathrm{~g}^{-1}$, which indicates that magnesium anodes could deliver a large number of electrons per unit mass. ${ }^{\mathbf{1} 2}$ The outstanding characteristics of $\mathrm{Mg}$ and its alloys make them attractive in energy storage devices along with their environmental friendliness, easy machining and nontoxicity. ${ }^{3,4}$ However, the intrinsic problems of self-corrosion ${ }^{5}$ and negative difference effect (NDE) limit their practical current efficiency in aqueous solutions. ${ }^{6-9}$ These problems have been considered as prime suppression factors for the exploitation of magnesium and its alloys as successful negative electrodes. Another major obstacle for magnesium alloys is delayed action, ${ }^{10}$ caused by a hydroxide layer ${ }^{11-14}$ passive film which is spontaneously formed on the electrode surface in aqueous solution, due to the high chemical and electrochemical activity of $\mathrm{Mg}$ alloys. To overcome the above said problems related to $\mathrm{Mg}$ alloys, different techniques have been employed such as composite electrolytes and inhibitors. ${ }^{\mathbf{1 5}}$

${ }^{a}$ College of Chemistry and Chemical Engineering, Chongqing University, Chongqing 400044, P. R. China.E-mail: cgchen@cqu.edu.cn

${ }^{b}$ Department of Applied Physics, Chongqing University, Chongqing 400044, P. R. China ${ }^{c}$ Department of Physics, COMSATS Institute of Information Technology, Lahore 54000, Pakistan
Based on the previous literatures, there are different kinds of magnesium alloys selected as promising candidates for negative electrode for $\mathrm{Mg}$ batteries. Song et al. ${ }^{\mathbf{1 6 - 1 9}}$ systematic discussed the corrosion behavior and mechanism of AZ Mg alloy in sodium chloride, the various content of aluminum ( $\mathrm{Al}$ ) displayed great difference in electrochemical behavior. The influence of microstructure and composition on the corrosion behavior of $\mathrm{Mg}-\mathrm{Al}$ alloys in chloride media had been studied by Pardo group. ${ }^{20}$ Among earlier studies, the AZ31B Mg alloy with the composition of $\mathrm{Al}-3 \mathrm{wt} \% \mathrm{Zn}-1 \mathrm{wt} \%$ and balance $\mathrm{Mg}$ shows relatively lower discharge potential, higher current efficiency, and shorter delayed time compared with AZ21 and AZ61. ${ }^{21}$ Consequently, there are many researchers pay attention to the electrochemical behavior of AZ31B alloy as electrode material in energy source. Shi et al. ${ }^{22}$ studied the electrochemical behavior of AZ31B magnesium alloy in the electrolyte of $\mathrm{MgSO}_{4}$, $\mathrm{Mg}\left(\mathrm{ClO}_{4}\right)_{2}$ and $\mathrm{Mg}\left(\mathrm{NO}_{3}\right)_{2}$, respectively. The results demonstrated that AZ31B magnesium alloy obtained excellent corrosion resistive performance and considerable discharge efficiency in $\mathrm{Mg}\left(\mathrm{NO}_{3}\right)_{2}$ aqueous solution. Another efficient approach to enhance the electrochemical performance of $\mathrm{Mg}$ alloy in aqueous solution is surface engineering, which includes the surface coating by wet process (anodization); plating and chemical conversion. ${ }^{23-26}$ The present work has been undertaken to adopt chemical treatment of $\mathrm{Mg}$ alloy which is helpful and simple approach to improve the electrochemical properties of surface film. In addition, the inhibitor is a useful way to 
change corrosion process of $\mathrm{Mg}$ alloy, specifically; a small amount of inhibitor appears to be able to restrain the corrosion rate of $\mathrm{Mg}$ alloy in solution. Sodium fluoride (NaF) as an effective inhibitor had been widely used in anti-corrosion field, because of its stronger adsorption than hydroxyl on metal surface. $^{23,25}$ Reviewing the literature, to best our knowledge there are no reports paid attention to realize the importance of $\mathrm{NaF}$ on corrosion behavior, anodic efficiency and discharge activity for AZ31B $\mathrm{Mg}$ alloy in $\mathrm{MgSO}_{4}-\mathrm{Mg}\left(\mathrm{NO}_{3}\right)_{2}$ composite electrolyte.

This work aim to acquire detailed information about AZ31B $\mathrm{Mg}$ alloy in $\mathrm{MgSO}_{4}-\mathrm{Mg}\left(\mathrm{NO}_{3}\right)_{2}$ composite solution electrolyte and further optimized the results with different concentration of NaF. Moreover, establishing the relevant connection of electrochemical behavior with their corrosion film structure, using conventional electrochemical techniques and surface analysis methods, including Scanning Electron Microscopy (SEM), Fourier Transform Infrared (FT-IR) spectroscopy and Xray Photoelectron Spectroscopy (XPS). The analysis results indicate that the optimization of electrolyte helps to improve the corrosion resistance and discharge activation issue, and therefore accelerating the practical application of $\mathrm{Mg}$ alloy materials in batteries fields.

\section{Experimental}

\subsection{Materials and experimental}

All chemicals were of analytical grade. Magnesium nitrate hexahydrate $\left(\mathrm{Mg}\left(\mathrm{NO}_{3}\right)_{2} \cdot 6 \mathrm{H}_{2} \mathrm{O}, 99.0 \%\right)$, magnesium sulfate anhydrous ( $\mathrm{MgSO}_{4}, 99.0 \%$ ), sodium fluoride (NaF, 98\%). AZ31B $\mathrm{Mg}$ alloy was purchased from Ao-Xin Anticorrosion Materials Co, Ltd. (Jiaozuo, China). The chemical composition of the alloy was (wt $\%$ ) $3 \% \mathrm{Al}, 1 \% \mathrm{Zn}, 0.2 \% \mathrm{Mn}$, and balance $\mathrm{Mg}$. The dimensions of the working electrodes were $\left(1 \times 1 \times 0.6 \mathrm{~cm}^{3}\right)$ linked with copper wire and embedded in epoxy resin used in the experiments, with exposed surface area of $1 \mathrm{~cm}^{2}$. The aqueous electrolyte was prepared by the mixture of different volume ratio of $2 \mathrm{~mol} \mathrm{~L}^{-1} \mathrm{MgSO}_{4}$ and $2 \mathrm{~mol} \mathrm{~L}^{-1} \mathrm{Mg}\left(\mathrm{NO}_{3}\right)_{2}$. The additive amount of $\mathrm{NaF}$ in the optimum proportion composite solution was $0-50 \mathrm{mmol} \mathrm{L}^{-1}$. Before each experiment, working electrodes were grounded with 200\#, 400\#, 600\#, 800\#, and $1000 \#$ SiC grit papers, subsequently, cleaned in deionized water for several times and dried at room temperature.

\subsection{Electrochemical measurements}

The electrochemical measurements were carried out using CHI660A (USA) electrochemistry workstation. The three electrode system adopted with graphite rod as counter electrode (CE), saturated calomel electrode (SCE) as reference electrode (RE) and tested sample as working electrode (WE). The Lugging capillary was used in order to reduce $I R$ drop effects in all measurements. Linear potential sweep voltammetric curves (LSV) results were collected after the samples were immersed for 5 days in composite electrolyte of $\mathrm{MgSO}_{4}$ and $\mathrm{Mg}\left(\mathrm{NO}_{3}\right)_{2}$ at different volume ratios, with a sweep rate of $1 \mathrm{mV} \mathrm{s}^{-1}$. The rest of electrochemical tests were conducted in composite electrolyte solutions with different concentration of $\mathrm{NaF}$ and the specimens were primarily immersed in the solutions for 1200 s. Tafel polarization curves were carried out with scan potential range of -1.5 to $0 \mathrm{~V}(v s$. SCE) and a sweep rate of $0.5 \mathrm{mV} \mathrm{s}^{-1}$. The galvanostatic potential-time curves were recorded at the applied anodic current densities of $2.5 \mathrm{~mA} \mathrm{~cm}^{-2}$ and the discharge time was $120 \mathrm{~s}$. Electrochemical impedance spectroscopy (EIS) results were obtained at open circuit potentials in the frequency range of $10^{5}$ to $10^{-2} \mathrm{~Hz}$ with a sinusoidal signal perturbation of $5 \mathrm{mV}$. The EIS data were fitted using Zview software. Weight loss experiments were measured in 200 $\mathrm{mL}$ glass beaker at $298 \mathrm{~K}$. The weighted samples were immersed in tested solution. The corrosion products on the surface were removed using a reagent of $20 \%$ (wt) chromic acid. The mean corrosion rates were calculated by immersion time, superficial area and weight loss of each sample.

The surface morphology of the specimens was characterized by a scanning electron microscopy (SEM) with accelerating voltage of $20 \mathrm{kV}$. The chemical composition of the corrosion product films on the electrode formed in the electrolytes were investigated by FT-IR spectrophotometer (Nicolet 550II, USA). XPS (Axis Ultra, Kratos Analytical, Led, Britain) was used for the surface chemical analysis. Initial survey spectrum was obtained with the analyzer pass energy set to $280 \mathrm{eV}$. The X-ray source and beam size in this case were monochromatic $\mathrm{Al} \mathrm{K} \alpha$ radiation ( $h \nu$ $=1486.6 \mathrm{eV}$ ) and $100 \mu \mathrm{m}$, respectively.

\section{Results and discussion}

\subsection{Polarization behavior of AZ31B $\mathrm{Mg}$ alloy in the solution of $\mathrm{MgSO}_{4}: \mathrm{Mg}\left(\mathrm{NO}_{3}\right)_{2}$}

Fig. 1 shows the comparison of linear potential sweep voltammetric (LSV) polarization curves for AZ31B $\mathrm{Mg}$ alloy in composite electrolyte solutions of $\mathrm{MgSO}_{4}-\mathrm{Mg}\left(\mathrm{NO}_{3}\right)_{2}$ with different volume ratios [0:100 (a); $7: 93$ (b); $20: 80$ (c); $60: 40$ (d); $80: 20$ (e); $100: 0$ (f)]. The activation electrode potential $\left(E_{\text {act }}\right)$ is a certain potential value where activity reaction starts accompany with express increase in the anodic current and hydrogen gas release. Anodic polarization scan of AZ31B alloy samples have a knee point, appearing at a certain potential value depend on the solution nature. The relatively negative

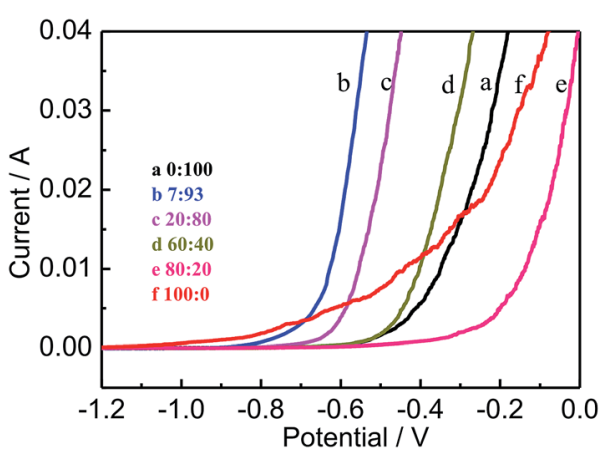

Fig. 1 LSV curves of AZ31B Mg alloys in different volume ratio of $\mathrm{MgSO}_{4}: \mathrm{Mg}\left(\mathrm{NO}_{3}\right)_{2} ; 0: 100$ (a), $7: 93$ (b), $20: 80$ (c), $60: 40$ (d), $80: 20$ (e) and $100: 0$ (f). 
Table 1 Electrochemical data of AZ31B electrode in composite electrolyte solutions

\begin{tabular}{llllll}
\hline Volume ratio $\left(\mathrm{MgSO}_{4}: \mathrm{Mg}\left(\mathrm{NO}_{3}\right)_{2}\right)$ & $0: 100$ & $7: 93$ & $20: 80$ & $60: 40$ & $80: 20$ \\
$E_{\text {ocp }}(\mathrm{V})$ & -1.372 & -1.497 & -1.532 & -1.582 & -1.614 \\
$E_{\text {act }}(\mathrm{V})$ & -0.386 & -0.649 & -0.581 & -0.438 & -0.148
\end{tabular}

value of $E_{\text {act }}$ presents an excellent discharge performance of $\mathrm{Mg}$ alloy electrode. As illustrates in Fig. 1, the value of active potential becomes negative firstly and then shifts to a positive direction with the increase of $\mathrm{MgSO}_{4}$. It is evidently observes that the minimum value of active potential presents at the special solution of $\mathrm{MgSO}_{4}: \mathrm{Mg}\left(\mathrm{NO}_{3}\right)_{2}=7: 93$. The mixture of $\mathrm{MgSO}_{4}$ has apparently impact on the value of active potential while makes no effect on the polarization resistance, which is beneficial to discharge process of $\mathrm{Mg}$ alloy. ${ }^{27} \mathrm{LSV}$ polarization results demonstrate that the composite solution has comprehensive property of enhance the electrochemical activity for AZ31B Mg alloy.

Open circuit potential $\left(E_{\text {ocp }}\right)$ and activation potential $\left(E_{\text {act }}\right)$ for AZ31B Mg alloy in composite solutions of $\mathrm{MgSO}_{4}-\mathrm{Mg}\left(\mathrm{NO}_{3}\right)_{2}$ with different volume ratios are summarized in Table 1 . The corrosion product film formed on the metal surface during open-circuit immersion may lead to spontaneous passivation of magnesium alloy and also responsible for the shift of $E_{\text {ocp }}$ and $E_{\text {act }}$ to a positive direction. The deposition of corrosion product on interaction between the electrolyte and metal surface can effectively seals the surface against for further corrosion. As shown in Table $1, \mathrm{Mg}\left(\mathrm{NO}_{3}\right)_{2}$ solution has the highest value of $E_{\text {ocp }}(-1.372 \mathrm{~V})$ while the $\mathrm{MgSO}_{4}$ solution has a relatively lower value of $E_{\text {ocp }}$, which indicate that the film formation rate in $\mathrm{Mg}\left(\mathrm{NO}_{3}\right)_{2}$ electrolyte is high as compared with $\mathrm{MgSO}_{4}$ solution. On the other perspective, this results reveal that $\mathrm{SO}_{4}{ }^{-}$ions is more aggressive than $\mathrm{NO}_{3}{ }^{-}$ions, which results that the activate reaction is easy to occur in solution containing $\mathrm{SO}_{4}{ }^{-}$ions. ${ }^{28}$ The accelerate of activate process by $\mathrm{SO}_{4}{ }^{-}$ions, resulting a large negative shift in $E_{\text {ocp }}$ and $E_{\text {act }}$, the maximum shift value of $E_{\text {ocp }}$ is $242 \mathrm{mV}$ at $80 \%$ volume ratio of $\mathrm{MgSO}_{4}$. On the whole, the $\mathrm{AZ31B}$ $\mathrm{Mg}$ alloy in solution with $\mathrm{MgSO}_{4}: \mathrm{Mg}\left(\mathrm{NO}_{3}\right)_{2}=7: 93$ not only exhibits the high discharge activity, but also has excellent corrosion resistance which are significantly superior to any single solution of $\mathrm{Mg}\left(\mathrm{NO}_{3}\right)_{2}$ or $\mathrm{MgSO}_{4}$.

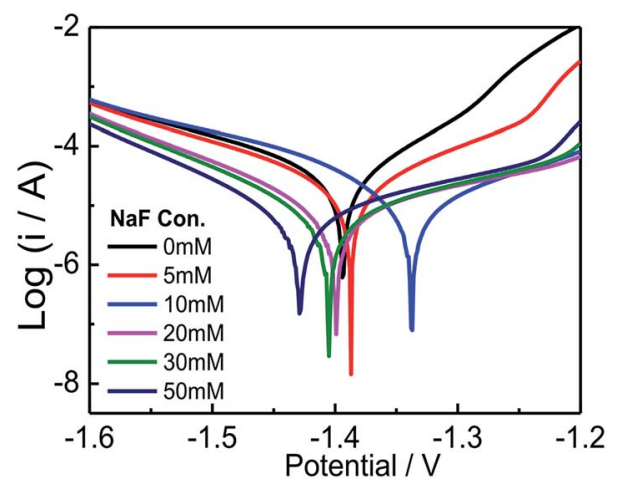

Fig. 2 Tafel curves of AZ31B alloy in composite solution $\left(\mathrm{MgSO}_{4}: \mathrm{Mg}\left(\mathrm{NO}_{3}\right)_{2}=7: 93\right)$ with different concentrations of $\mathrm{NaF}$.

\subsection{Tafel behavior of additive NaF}

Potentiodynamic polarization test is used to explore the passivation effects of NaF on AZ31B alloy in composite solution and the relevant results are presented in Fig. 2. It is established that, as $\mathrm{NaF}$ is introduced to the solution, the corrosion potential $\left(E_{\text {corr }}\right)$ shifts towards the negative direction and reduces the anodic current densities $\left(I_{\text {corr }}\right)$. The cathodic reaction of $\mathrm{Mg}$ alloy in aqueous solution produce $\mathrm{H}_{2}$ and anodic reaction process can attribute to the dissolution of $\mathrm{Mg}$ as described in eqn (1) and (2) respectively. ${ }^{29}$

$$
\begin{gathered}
2 \mathrm{H}_{2} \mathrm{O}+2 \mathrm{e}^{-} \rightarrow 2 \mathrm{OH}^{-}+\mathrm{H}_{2} \\
\mathrm{Mg} \rightarrow \mathrm{Mg}^{2+}+2 \mathrm{e}^{-}
\end{gathered}
$$

Generally, the lower corrosion current density accompany with the more positive corrosion potential represent better corrosion resistance.$^{30}$ However, it is abnormal to found that the $I_{\text {corr }}$ rapidly decrease while the $E_{\text {corr }}$ gradually shifts to a negative direction with $\mathrm{NaF}$ in composite solutions. This phenomenon explained by the unique behavior of magnesium which called "negative difference effect". ${ }^{29,30}$ It is clearly seen that the presence of NaF does not change the shape of the cathodic branch, but only has influence on anodic polarization area (Fig. 2), revealing that $\mathrm{NaF}$ can restrain the anode reaction, belong to typical anodetype inhibitor for AZ31B Mg alloy in such condition.

The values of corrosion potential and corrosion current density obtained by means of extrapolated up the intersection point on the Tafel curve. The fitting parameters are compared with composite electrolyte without $\mathrm{NaF}$ and summarized in Table 2. The corrosion current densities decrease sharply when different concentrations of NaF are introduced. Moreover, the corrosion current density of solution containing $\mathrm{NaF}$ at concentration exceeded $20 \mathrm{mmol} \mathrm{L} \mathrm{L}^{-1}$ are obvious lower than without NaF. These results reveal that the reaction of hydrogen corrosion cause some corrosion pits or holes formation on the surface of $\mathrm{Mg}$ alloy electrode, ${ }^{31}$ which would be covered by $\mathrm{MgF}_{2}$ sediments of reaction with $\mathrm{NaF}$ with $\mathrm{Mg}^{2+}$ or $\mathrm{Mg}(\mathrm{OH})_{2}$ that would be further confirm by SEM, FTIR and XPS.

Table 2 The fitting date AZ31B in the composite electrolyte with $\mathrm{NaF}$

\begin{tabular}{lll}
\hline $\mathrm{NaF}\left(\mathrm{mmol} \mathrm{L}^{-1}\right)$ & $I_{\text {corr }}\left(10^{-5} \mathrm{~A} \mathrm{~cm}^{-2}\right)$ & $E_{\text {corr }}(\mathrm{V})$ \\
\hline 0 & 2.525 & -1.393 \\
5 & 2.209 & -1.387 \\
10 & 1.425 & -1.337 \\
20 & 0.965 & -1.399 \\
30 & 0.783 & -1.405 \\
50 & 0.768 & -1.429
\end{tabular}


Table 3 Weightlessness experiment data of AZ31B in composite solution with $\mathrm{NaF}$

\begin{tabular}{llll}
\hline $\begin{array}{l}\mathrm{NaF} \\
(\mathrm{mmol} \mathrm{L}\end{array}$ & $\begin{array}{l}\text { Weight loss } \\
(\%)\end{array}$ & $\begin{array}{l}\text { Corrosion rate } \\
\left(10^{-5} \mathrm{~g} \mathrm{~cm}^{-2} \mathrm{~h}^{-1}\right)\end{array}$ & $\begin{array}{l}\text { Inhibition rate } \\
(\%)\end{array}$ \\
\hline 0 & 0.94 & 4.76 & 0 \\
5 & 0.53 & 2.65 & 43 \\
10 & 0.74 & 3.80 & 19 \\
20 & 0.59 & 3.01 & 36 \\
30 & 0.20 & 0.99 & 80 \\
50 & 0.20 & 1.01 & 78
\end{tabular}

\subsection{Weight loss measurement}

Weight loss measurement is commonly applied for comparing the self-corrosion rate of metal material in different electrolytes. Table 3 presents the corrosion rate and corresponding inhibition efficiency of AZ31B Mg alloy immerse in composite electrolyte with various concentration of NaF for 48 hours. The inhibition rate $(\eta)$ can be calculated as follows: ${ }^{32}$

$$
\eta=\frac{w^{\mathrm{o}}-w}{w^{\mathrm{o}}} \times 100
$$

where $w^{\circ}$ and $w$ are the corrosion rates of Mg alloy without and with the inhibitor, respectively. The corrosion rate significant reduces and inhibitor efficiency improve distinctly with the increasing concentration of NaF. It is worth noting that the corrosion rate of $\mathrm{Mg}$ alloy in blank electrolyte is $4.76 \times 10^{-5} \mathrm{~g}$ $\mathrm{cm}^{-2} \mathrm{~h}^{-1}$, while the value reduces to $0.99 \times 10^{-5} \mathrm{~g} \mathrm{~cm}^{-2} \mathrm{~h}^{-1}$ in the solution including $30 \mathrm{mmol} \mathrm{L}^{-1} \mathrm{NaF}$. Moreover, the corrosion rate is reduced by 4.8 times and the inhibition efficiency increases up to $80 \%$ when the concentration of $\mathrm{NaF}$ is reached

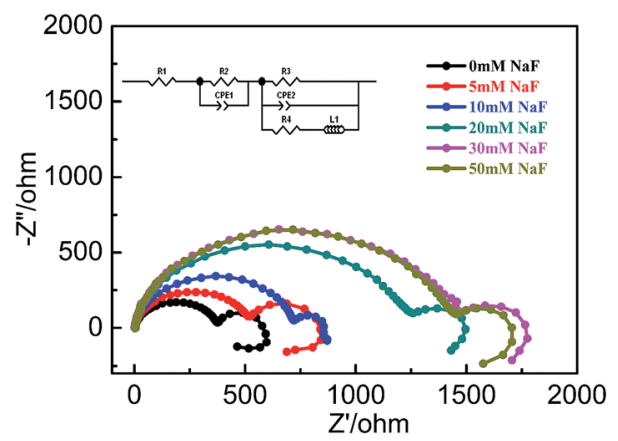

Fig. 3 EIS plots of AZ31B Mg alloy in composite electrolyte solution $\left(\mathrm{MgSO}_{4}: \mathrm{Mg}\left(\mathrm{NO}_{3}\right)_{2}=7: 93\right)$ with different concentrations of $\mathrm{NaF}$. to $30 \mathrm{mmol} \mathrm{L}^{-1}$. The results indicate that the presence of $\mathrm{NaF}$ is restrained the corrosion reaction and improve the corrosion resistance of $\mathrm{Mg}$ alloy electrode.

\subsection{Electrochemical impedance spectroscopy}

The Nyquist plots of electrochemical impedance spectroscopy (EIS) of AZ31B Mg alloy acquired at open circuit potential and presented in Fig. 3 along with Zview simulated circuit. The Nyquist plots are characterized by two semicircles at high and medium frequencies, followed by an inductive loop in the lower frequency range. The highly similar shapes suggest that the addition of NaF only changes the properties of corrosion film and has no impact on the film formation mechanism. The two semicircular diameters are defined by transfer resistance and electric double layer capacitance, separately. ${ }^{33,34}$ Due to the deposition and dissolution of the corrosion products, bring the inductive loop at lower frequency, these diffusion process called "diffusion admittance". ${ }^{35}$ This phenomenon indicates that the change in capacitance on rough surface electrode and its equivalent circuit can represents in CPE. Diameter of the arc of the capacitive reactance gradual increase with the addition of $\mathrm{NaF}$ and reaches to a stable stage at $C_{\mathrm{NaF}} \geq 30 \mathrm{mmol} \mathrm{L}^{-1}$. EIS results could be illustrated as equivalent circuit of $\left[R_{1}\left(\mathrm{CPE}_{1} \times\right.\right.$ $\left.\left.R_{2}\right)\left(\mathrm{CPE}_{2} \times R_{3}\right)\right]$ as shown in inset of Fig. 3. $R_{1}$ is the solution resistance, $R_{2}$ is the charge transfer resistance, CPE $\mathrm{C}_{1}$ represents the electric double layer capacitance; $R_{3}$ and $\mathrm{CPE}_{2}$ are the film resistance and capacitance of the surface passive film on the anode, respectively. ${ }^{36} \mathrm{CPE}_{1}$ and $\mathrm{CPE}_{2}$ are the diffusion capacitance caused by irregular oxide film of alloy surface. $\mathrm{CPE}_{1}$ is related to contribution from the capacitance of the outer layer and the faradic reaction, $\mathrm{CPE}_{2}$ comes from the inner layer, while $R_{2}$ and $R_{3}$ are the respective resistance of the outer and inner layers constituting the surface film, respectively. The appearance of inductive impedance component $L$ and $R_{4}$ suggesting the presence of stripping absorption process of the intermediate products on the surface of the electrode. Its relevant fitting results are presented in Table 4.

$R_{2}$ increases with the addition of $\mathrm{NaF}$, the largest resistance value $\left(1446 \Omega\right.$ ) appears at concentration of $\mathrm{NaF}$ is $30 \mathrm{mmol} \mathrm{L}^{-1}$, compared with blank electrolyte $(376 \Omega)$. The value of resistance at $30 \mathrm{mmol} \mathrm{L}^{-1}$ of $\mathrm{NaF}$ which is increased by 4 times as compared without NaF. This phenomena is attributed to the possible formation of a less soluble $\left(K_{\mathrm{sp}}=5.16 \times 10^{-11}\right)$ and more stable $\left(\Delta G_{\mathrm{f}}^{0}=-1071.1 \mathrm{~kJ} \mathrm{~mol}^{-1}\right)$ magnesium fluoride passive film, through the following reaction. ${ }^{37}$

Table 4 Parameters obtained from ElS fitting

\begin{tabular}{lllllll}
\hline $\mathrm{NaF}\left(\mathrm{mmol} \mathrm{L}^{-1}\right)$ & $R_{1}(\Omega)$ & $\mathrm{CPE}_{1}-T\left(\mu \mathrm{F} \mathrm{cm}^{-2}\right)$ & $\mathrm{CPE}_{1}-P$ & $R_{2}(\Omega)$ & $\mathrm{CPE}_{2}-T\left(\mathrm{~F} \mathrm{~cm}^{-2} 10^{-3}\right)$ & $\mathrm{CPE}_{2}-P$ \\
\hline 0 & 3.12 & 11.96 & 0.931 & 376 & 3.35 & 1.02 \\
5 & 2.80 & 11.14 & 0.941 & 519 & 1.77 & 1.02 \\
10 & 2.05 & 7.06 & 0.959 & 720 & 4.58 & 3.10 \\
20 & 2.20 & 9.96 & 0.919 & 1228 & 5.22 & 132 \\
30 & 3.75 & 8.82 & 0.929 & 1446 & 8.02 & 0.91 \\
50 & 5.49 & 8.04 & 0.928 & 1435 & 6.76 & 276 \\
\end{tabular}




$$
\mathrm{Mg}(\mathrm{OH})_{2}+2 \mathrm{~F}^{-} \rightarrow \mathrm{MgF}_{2} \downarrow+2 \mathrm{OH}^{-}
$$

The results exhibit the sharp increase in resistance of covered layer, under a low concentration range upto $30 \mathrm{mmol}$ $\mathrm{L}^{-1} \mathrm{NaF}$. However, obviously decrease of corrosion resistance for surface film when fluoride concentrations higher than $30 \mathrm{mmol} \mathrm{L}^{-1}$. These results are consistent with the decrease of $E_{\text {corr }}$ value for $\mathrm{Mg}$ alloy and also with previous reports. ${ }^{38}$ Moreover, the results obtained from EIS plot are well agreed with mass loss measurement. Thus, there is significant improvement for corrosion resistance of AZ31B alloy in composite solution with $\mathrm{NaF}$. This is likely as $\mathrm{F}^{-}$ion promotes the formation of fluorinated salt film that refines the surface microstructure and enhances the protective effectiveness of the corrosion products.

\subsection{Galvanostatic discharge}

The discharge properties of magnesium alloy are tested in composite solution with different concentration of $\mathrm{NaF}$ and can clearly expression via its potential-time curve, which measured by galvanostatic discharge at a constant anodic current density and shown in Fig. 4. The detail parameters of discharge curves are listed in Table 5. The surface film formation process of $\mathrm{Mg}$ electrode in aqueous solution consist three stages: film-grow, film-expand and film-breakdown. ${ }^{39}$ The thicker film can protect alloy from further corrosion, but it may aggravate the delayed action. This phenomenon possibly due to the thicker film requires a high dilatation stress. Thus, it needs a longer time for anodic current flow to the initiate film breakdown. At the initial phase of discharge process, electrode surface would produce a large number of bubbles, after several seconds, the discharge voltage gradually reaches to a steady state and the discharge potential apparent changed with the addition of NaF. The discharge potential first shifts towards negative and then gradually increases, moreover, the maximum negative shift value is $190 \mathrm{mV}$ when the concentration of $\mathrm{NaF}$ reaches at $30 \mathrm{mmol} \mathrm{L}^{-1}$. A relatively negative discharge potential of $\mathrm{Mg}$ alloy is normally associated with a strong ability to deliver electrons for energy supply. It can be clearly seen in Table 5 , the delayed time is obviously shortened from $2.8 \mathrm{~s}$ to $0.7 \mathrm{~s}$ at the

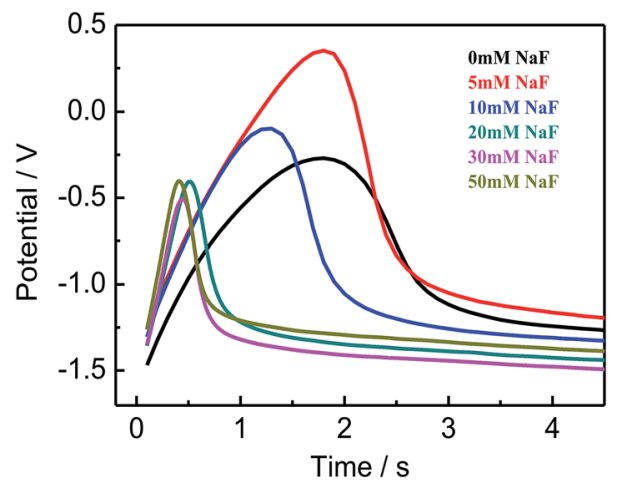

Fig. 4 Discharge curves of AZ31B Mg alloy in composite electrolyte $\left(\mathrm{MgSO}_{4}: \mathrm{Mg}\left(\mathrm{NO}_{3}\right)_{2}=7: 93\right)$ containing different $\mathrm{NaF}$ concentrations.
Table 5 Parameters obtained from discharge curves

\begin{tabular}{llll}
\hline $\begin{array}{l}\mathrm{NaF} \\
\left(\mathrm{mmol} \mathrm{L}^{-1}\right)\end{array}$ & $\begin{array}{l}\text { Potential drop } \\
(\mathrm{V})\end{array}$ & $\begin{array}{l}\text { Discharge potential } \\
(\mathrm{V})\end{array}$ & $\begin{array}{l}\text { Delay time } \\
(\mathrm{s})\end{array}$ \\
\hline 0 & 1.11 & -1.35 & 2.84 \\
5 & 1.76 & -1.26 & 2.55 \\
10 & 1.31 & -1.41 & 2.02 \\
20 & 0.98 & -1.49 & 0.81 \\
30 & 1.03 & -1.54 & 0.72 \\
50 & 1.11 & -1.44 & 0.68
\end{tabular}

concentration of $30 \mathrm{mmol} \mathrm{L}^{-1} \mathrm{NaF}$, and the best corrosion resistance also appear at this condition (Section 3.4). It seemingly go against the above mentioned film-thickening mechanism that delayed time prolonged with the increase of corrosion resistance. In fact, it may be speculated that the accumulation of corrosion products on $\mathrm{Mg}$ anode behave as a homogeneous thin film rather than a coherent passive film, which can efficiently improve the corrosion resistance and eliminate the delayed action of the anode. The negative shift of potential represents an excellent discharge performance, indicating that the corrosion product film more easily to breakdown and fall off during the discharge process. This meaningful consequences such as a more negative discharge potential and a fairly short delayed time provide abundant evidences that the $\mathrm{MgSO}_{4}{ }^{-}$ $\mathrm{Mg}\left(\mathrm{NO}_{3}\right)_{2}$ composite electrolyte with $30 \mathrm{mmol} \mathrm{L}^{-1} \mathrm{NaF}$ can serve as a suitable solution for $\mathrm{Mg}-\mathrm{MnO}_{2}$ primary batteries.

\subsection{SEM analyses of the surface film}

The SEM images of AZ31B Mg alloy in composite solution without and with NaF after immersion for 5 days are shown in Fig. 5a and b, respectively. AZ31B Mg alloy display network-like structure in both solutions, the microcracks occurring on alloy surface may caused by desorption of water during the drying process, which hardly observed in an optical microscope immediately after withdrawal the samples from solution. ${ }^{40,41}$ The surface of electrode is covered by corrosion layer with different degrees of cracks in solution without $\mathrm{NaF}$ inhibitor, suggesting that strongly corroded as compared with solution include $\mathrm{NaF}\left(30 \mathrm{mmol} \mathrm{L}^{-1}\right)$, which exhibits a relatively flat and thinner corrosion product film. Based on the previous study, the thicker film layer with wider crack openings and larger microcracks which is bad for corrosion resistance and discharge activity. ${ }^{42}$ Thus, the thick and dense corrosion products of AZ31B alloy formed in solution (a) may reduce the active electrode area and hinder the discharge process, which results in a decline of the discharge activity and lower the current efficiency of $\mathrm{Mg}$ alloy. Moreover, the inferior corrosion resistance is ascribed to its larger microcracks and wider crack openings. As expected, the obtained information from SEM image are highly accordance with the above-mentioned electrochemical properties. Fig. 5b shows that the AZ31B Mg alloy immersed in solution (b) exhibited a similar surface morphology with solution (a), however, obviously reduced the crack openings and smaller microcracks. Consequently, NaF brings a large change in micro- 

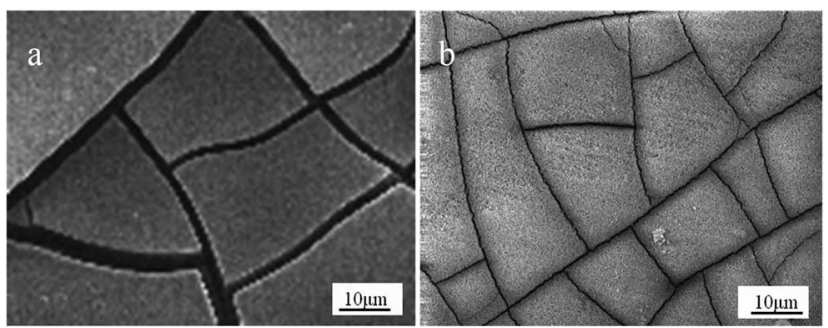

Fig. 5 SEM images of AZ31B Mg alloy in electrolyte solution without (a) and with (b) $\mathrm{NaF}$ for 5 days.

structure of outermost layer of extremely protective film and accelerates the formation of uniform surface film which serves as a nature screen between magnesium electrolyte and corrosive medium. We suppose that $\mathrm{F}^{-}$ion is easily adsorbed on the weak parts of the surface film and react with $\mathrm{Mg}^{2+}$ to form a more stable corrosion product $\mathrm{MgF}_{2}$ on the surface of $\mathrm{Mg}$ alloy electrode, which can evidently prevents $\mathrm{Mg}$ alloy electrode from further corrosion.

\subsection{FT-IR spectroscopic analysis of the surface film}

In this study, the nature of the corrosion layer is investigated by Fourier transform infrared spectroscopy (FT-IR). The typical FT-

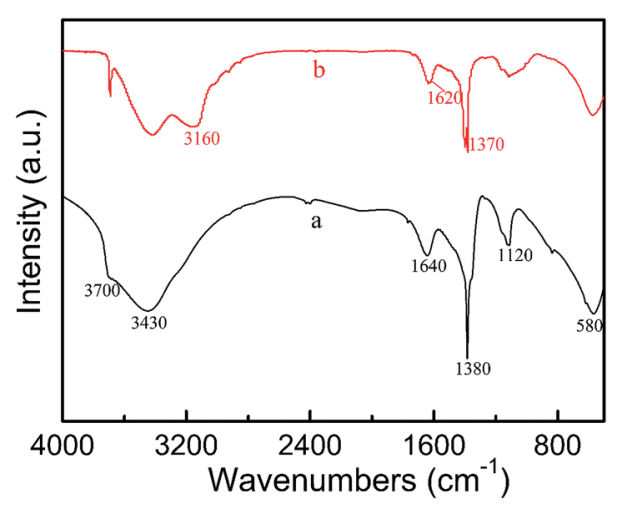

Fig. 6 FT-IR spectra of corrosion products on AZ31B magnesium alloy in composite electrolyte solution (a) without and (b) with $30 \mathrm{mmol} \mathrm{L}^{-1}$ $\mathrm{NaF}$ after 5 days of immersion.
IR transmission spectrum at wavenumbers range of 500-4000 $\mathrm{cm}^{-1}$ for AZ31B Mg alloy in composite solution without (a) and with $30 \mathrm{mmol} \mathrm{L}^{-1} \mathrm{NaF}$ (b) after 5 days of immersion are displayed in Fig. 6. This spectra is analyzed to acquire some valuable information for the effect of $\mathrm{NaF}$ on the composition of surface film. It can be clearly seen in Fig. 6, both of deposited films have highly similar absorption spectrum. As discussed in detail here, the three peaks at $1380 \mathrm{~cm}^{-1}, 1640 \mathrm{~cm}^{-1}, 3430 \mathrm{~cm}^{-1}$ demonstrate the presence of $\mathrm{NO}_{3}{ }^{-}$group. ${ }^{43}$ Furthermore, the strongest absorption at $1380 \mathrm{~cm}^{-1}$ represents the amorphous anhydrous magnesium nitrate. ${ }^{44} \mathrm{SO}_{4}{ }^{2-}$ ion is the five-atom tetrahedron group, and the two obvious characteristic adsorption peaks at $580 \mathrm{~cm}^{-1}, 1120 \mathrm{~cm}^{-1}$ attributing to the vibration of the absorption of functional group of $\mathrm{SO}_{4}{ }^{2-} \cdot{ }^{\mathbf{1 0 , 4 5}}$ It is interesting to found that the intensity of above groups for AZ31B alloy sample in solution (b) is notably weaker than solution (a). This phenomenon may due to the presence of $\mathrm{F}^{-}$ion affect the content of the other ions at a certain degree. As known, the bands of $\mathrm{OH}$ can observed in the range $3770-3400 \mathrm{~cm}^{-1}$ due to its stretching vibrations very sensitive to coordination environment. ${ }^{46} \mathrm{~A}$ characteristic absorption peak at $3700 \mathrm{~cm}^{-1}$ is associated with deposition of amorphous $\mathrm{Mg}(\mathrm{OH})_{2}$ on the surface of AZ31B Mg alloy. ${ }^{47}$ One should note, curve b shows a stronger absorption intensity of $\mathrm{Mg}(\mathrm{OH})_{2}$ compared with curve a, which may ascribes to the rapid formation process of corrosion film on the alloy through the additional of NaF. It is necessary to highlight the difference in Fig. 6, the three additional bands at $1370 \mathrm{~cm}^{-1}, 1620 \mathrm{~cm}^{-1}$ and $3160 \mathrm{~cm}^{-1}$ are only visibled in curve $\mathrm{b}$, which indicate the presence of $\mathrm{MgF}_{2} \cdot{ }^{48}$ Compared with standard spectrum, the slight shift of these peaks may caused by the superposition with $\mathrm{NO}_{3}{ }^{-}$peaks. Hence, it is concluded that the addition of NaF change the composition of corrosion film of $\mathrm{Mg}$ alloy, providing a powerful support for its electrochemical properties.

\subsection{XPS analysis of the surface film}

XPS is used to further study the composition of surface film deposited on the AZ31B Mg alloy. Fig. 7 presents the O 1s, Mg 2p and F 1s XPS spectras of the alloy surface film formed in composite electrolyte including $\mathrm{NaF}\left(30 \mathrm{mmol} \mathrm{L}^{-1}\right)$ with 5 days of immersion. The $\mathrm{O} 1 \mathrm{~s}$ spectra shows three peaks, one peak at
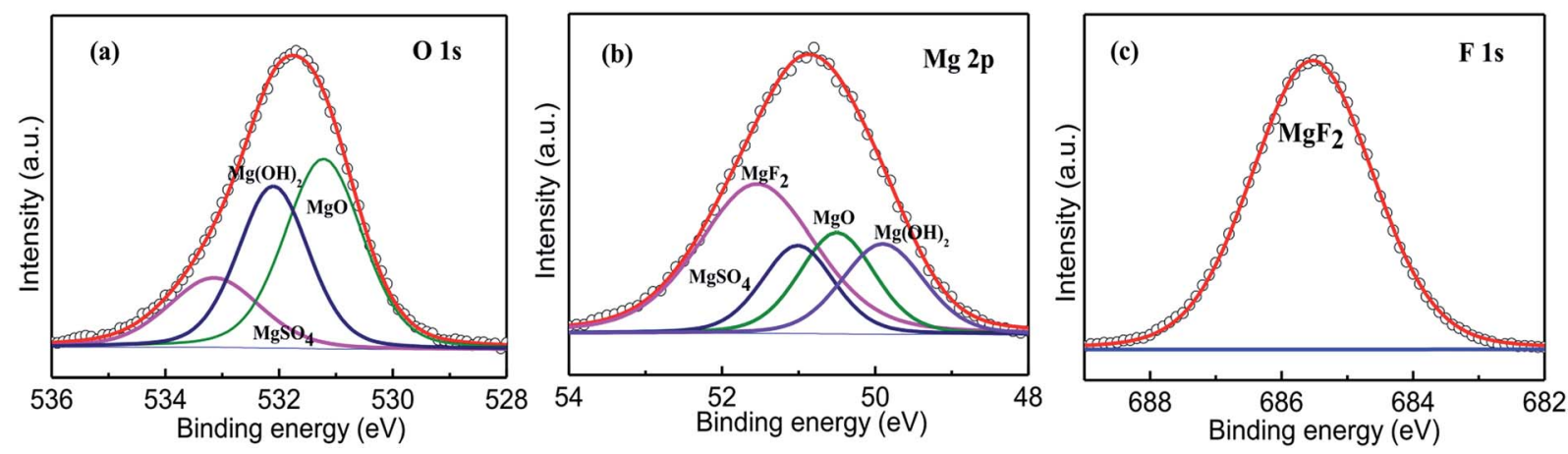

Fig. 7 XPS spectrums; O 1s (a), Mg 2p (b) and F 1s (c) XPS of surface film on AZ31B Mg alloy after 5 days of immersion in composite electrolyte solution contain $30 \mathrm{mmol} \mathrm{L}^{-1} \mathrm{NaF}$. 
$533.1 \mathrm{eV}$ is corresponding to the formation of $\mathrm{MgSO}_{4}$, while the remaining two peaks at $532.1 \mathrm{eV}$ and $531.2 \mathrm{eV}$ are attributed to the presence of $\mathrm{Mg}(\mathrm{OH})_{2}$ and $\mathrm{MgO} .{ }^{49-51}$ The XPS spectrum of $\mathrm{Mg}$ $2 \mathrm{p}$ is divided into four peaks at binding energies of $51.5 \mathrm{eV}$, $51.0 \mathrm{eV}, 50.5 \mathrm{eV}$, and $49.9 \mathrm{eV}$, corresponding to the existence of $\mathrm{MgF}_{2}, \mathrm{MgSO}_{4}, \mathrm{MgO}$ and $\mathrm{Mg}(\mathrm{OH})_{2}$, respectively. $\mathrm{F}$ 1s peak at binding energy of $685.6 \mathrm{eV}$ is identified as $\mathrm{MgF}_{2} \cdot{ }^{52}$ It is concluded that the mainly composition of corrosion product adhesion at alloy surface are $\mathrm{Mg}(\mathrm{OH})_{2}, \mathrm{MgO}, \mathrm{MgF}_{2}$ which are well consistent with FT-IR results.

\section{Conclusions}

In summary, electrochemical and corrosion behavior of AZ31B magnesium alloy have been investigated using electrochemical methods in composite solution of $\mathrm{MgSO}_{4}-\mathrm{Mg}\left(\mathrm{NO}_{3}\right)_{2}(0.14 \mathrm{~mol}$ $\left.\mathrm{L}^{-1} \mathrm{MgSO}_{4}, 1.86 \mathrm{~mol} \mathrm{~L}^{-1} \mathrm{Mg}\left(\mathrm{NO}_{3}\right)_{2}\right)$ under different sodium fluoride $(\mathrm{NaF})$ concentrations. The LSV polarization results indicate that the composite solutions clearly reduce the polarization resistance and improve the electrochemical reaction activity. Tafel curves analysis suggested that the NaF inhibitor in composite electrolyte can further reduce the corrosion rate, especially, the anodic corrosion current density significantly decrease from $4.76 \times 10^{-5} \mathrm{~g} \mathrm{~cm}^{-2} \mathrm{~h}^{-1}$ to $0.99 \times 10^{-5} \mathrm{~g} \mathrm{~cm}^{-2}$ $\mathrm{h}^{-1}$. The corrosion resistance increases with the addition of $\mathrm{NaF}$, the largest resistance value (1446 $\Omega$ ) appears at concentration of $\mathrm{NaF}$ is $30 \mathrm{mmol} \mathrm{L}^{-1}$, compared with blank electrolyte $(376 \Omega)$. The value of resistance at $30 \mathrm{mmol} \mathrm{L}^{-1}$ of $\mathrm{NaF}$ which is increased by 4 times as compared without NaF. The discharge potential of $\mathrm{Mg}$ alloy shift negatively and delay time shortened from $2.8 \mathrm{~s}$ to $0.4 \mathrm{~s}$, when the concentration of $\mathrm{NaF}$ reached at $30 \mathrm{mmol} \mathrm{L}^{-1}$ in the composite electrolyte. Therefore, the optimized concentration of inhibitor in composite electrolyte served as an excellent candidate for AZ31B Mg alloy applied in battery filed.

\section{Acknowledgements}

This work is supported by National Natural Science Foundation of China (No. 21273292).

\section{References}

1 C. G. Chen, Y. J. Shi, D. M. Yu, Y. P. Liu, Z. H. Yang, Q. Wang and L. Li, Trans. Nonferrous Met. Soc. China, 2006, 16, 782785.

2 G. G. Kumar and N. Munichandraiah, J. Power Sources, 2000, 91, 157-160.

3 R. Udhayan and P. B. Devendra, J. Power Sources, 1996, 63, 103-107.

4 Y. G. Tang, B. Y. Huang, L. B. Lu and D. R. Liu, Trans. Physics, 2004, 33, 85-89.

5 J. E. Gray and B. Luan, J. Alloys Compd., 2002, 336, 88-113. 6 N. G. Wang, R. C. Wang, C. Q. Peng, Y. Feng and B. Chen, Corros. Sci., 2012, 64, 17-27.

7 R. Balasubramanian, A. Veluchamy and N. Venkatakrishnan, J. Power Sources, 1994, 52, 305-308.
8 L. J. Liu and M. Schlesinger, Corros. Sci., 2009, 51, 17331737.

9 G. Song, A. Atrens, D. Stjohn and Y. Li, Corros. Sci., 1997, 39, 855-875.

10 L. Chen, C. G. Chen, N. N. Wang, Y. P. Liu, J. M. Wang, L. Deng and Q. L. Yang, J. Appl. Electrochem., 2014, 44, 773-779.

11 G. L. Song, A. Atrens, X. L. Wu and B. Zhang, Corros. Sci., 2005, 47, 769-791.

12 C. H. Peng, Battery Bimon., 2003, 33, 121-123.

13 R. M. Dell, Solid State Ionics, 2000, 134, 139-158.

14 L. Wang, S. Tadashi, B. P. Zhang and I. Hideo, J. Alloys Compd., 2009, 485, 747-845.

15 X. H. Chen, Y. X. Geng and J. Liu, J. Mater. Sci. Eng., 2013, 31, 148-152.

16 G. L. Song, J. Adv. Eng. Mater., 2005, 7, 563-586.

17 G. L. Song, A. Atrens, D. S. John and X. Wu, Corros. Sci., 1997, 39, 1981-2004.

18 G. L. Song, A. Atrens, X. Wu and B. C. Zhang, Corros. Sci., 1998, 40, 1769-1791.

19 A. Andrej, D. Matthew, G. L. Song, A. Atrens and M. I. Dargusch, Corros. Sci., 1991, 41, 249-273.

20 A. Pardo, M. C. Merino, A. E. Coy and F. Viejo, Electrochim. Acta, 2008, 53, 7890-7902.

21 A. Pardo, M. C. Merino, A. E. Coy, R. Arrabal and F. Viejo, Corros. Sci., 2008, 50, 823-834.

22 Y. G. Shi, Y. Zhang, S. F. Hu and Q. R. Chen, Corros. Prot., 2012, 33, 1051-1054.

23 D. Guo, Z. G. Fang and Z. D. Yang, Rare Met. Mater. Eng., 2008, 37, 1475-1478.

24 B. Ramezanzadeh and H. Vakili, J. Ind. Eng. Chem., 2015, 30, 225-233.

25 A. Kunitsugu, Corros. Sci., 2002, 44, 1375-1389.

26 H. Nobuyoshi, K. Yasuhiro and K. Daisuke, Corros. Sci., 2007, 49, 166-175.

27 X. S. Feng, Z. P. Xing, Y. J. Si and M. J. Li, Corros. Prot., 2007, 28, 553-555.

28 Y. G. Shi, Y. Zhang, S. F. Hu and Q. R. Chen, Corros. Prot., 2012, 33, 1051-1054.

29 Y. W. Song, E. H. Han and K. H. Dong, Corros. Sci., 2014, 88, 215-225.

30 L. Wang, L. Chen and Z. C. Yan, J. Alloys Compd., 2009, 480, 469-474.

31 T. T. Yan, L. L. Tan and D. S. Xiong, J. Mater. Sci. Eng., 2010, 30, 740-748.

32 Y. J. Qiang, S. T. Zhang and S. Y. Xu, RSC Adv., 2015, 5, 63866-63872.

33 M. S. Javed, R. Rizwan, A. Zishan, M. S. Rafique, S. Shamaila, S. F. Shaukat, et al., Int. J. Hydrogen Energy, 2016, 41, 30723078.

34 M. S. Javed, S. G. Dai, M. J. Wang, G. L. Guo, L. Chen, X. Wang and C. G. Hu, J. Power Sources, 2015, 285, 63-69.

35 G. Song and D. Stjohn, Corros. Sci., 2004, 46, 1381-1399.

36 N. Liu, J. L. Wang, L. D. Wang, Y. M. Wu and L. M. Wang, Corros. Sci., 2009, 51, 1328-1333.

37 F. EI Taib Heakal, N. S. Tantanwy and O. S. Shehata, Corros. Sci., 2012, 64, 153-163. 
38 F. EI Taib Heakal, A. M. Fekry and M. Z. Fatayerji, Electrochim. Acta, 2009, 54, 1545.

39 S. R. Narayanan and S. Sathyanarayana, J. Power Sources, 1988, 24, 295-327.

40 Z. Y. Yong, J. Zhu, Q. Cheng and Y. L. Liu, Appl. Surf. Sci., 2008, 255, 1672-1680.

41 C. S. Lin, C. Y. Lee, W. C. Li and Y. S. Chen, J. Electrochem. Soc., 2006, 153, B90-B96.

42 M. Mosiałek, G. Mordarski, P. Nowak, W. Simka, G. Nawrat, M. Hanke, R. P. Socha and J. Michalska, Surf. Coat. Technol., 2011, 206, 51-62.

43 H. A. Al-Abadleh and V. H. Grassian, J. Phys. Chem. B, 2003, 107, 10829-10839.

44 C. C. Addison and A. Walker, J. Chem. Soc., 1963, 1, 1120.
45 W. Alian, J. J. Freeman and R. Arvidson, Lunar and Planetary Science XXXIX, 2008, 2172, 1391.

46 J. Haber and M. Wojciechowska, J. Catal., 1988, 110, 23.

47 L. J. Yang, Y. H. Wei, L. F. Hou and D. Zhang, Corros. Sci., 2010, 52, 345-351.

48 http://webbook.nist.gov/chemistry/.

49 V. V. Maslyuk, C. Tegenkamp and H. Pfnu, J. Phys. Chem. A, 2005, 109, 4118-4124.

50 H. K. Hwang, C. H. Jeong, Y. J. Lee, Y. W. Ko and G. Y. Yeom, Surf. Coat. Technol., 2004, 178, 705-710.

51 L. Kanga, J. Gao, H. R. Xua, S. Q. Zhao, H. Chen and P. H. Wu, J. Cryst. Growth, 2006, 297, 100-104.

52 P. A. Sermon and R. Badheka, J. Sol-Gel Sci. Technol., 2004, 32, 149-153. 